\title{
STUDIES ON THE COMBINED USE OF MEASUREMENTS OF SWEAT ELECTROLYTE COMPOSITION AND RATE OF SWEATING AS AN INDEX OF ADRENAL CORTICAL ACTIVITY ${ }^{1}$
}

\author{
By WILLIAM LOCKE, 2 NATHAN B. TALBOT, HELEN S. JONES, AND \\ JANE WORCESTER \\ (From the Children's Medical Scrvice, Massachusetts General Hospital, the Department of \\ Pediatrics, Harvard Medical School, and the Department of Vital Statistics, Harvard \\ School of Public Health, Boston, Mass.)
}

(Submitted for publication October 25, 1950; accepted, January 2, 1951)

\section{INTRODUCTION}

Since Conn and his associates $(1,2)$ proposed that the concentration of chloride or sodium in thermal sweat can be used as an index of that function of the adrenal cortex concerned primarily with electrolyte metabolism, studies concerning the factors which are related to or influence the electrolytic composition of sweat have gained greatly in significance. In the past, several investigators have obtained data which suggested that the concentration of chloride in sweat is positively correlated with the rate of sweating $(3,4)$ and skin temperature (5). However, the relations of these variables to sweat electrolyte composition have never been defined with precision nor have they been studied in connection with the effect of adrenal cortical activity on the composition of sweat.

The present paper is concerned initially with studies which show that certain non-endocrine factors play a major role in the determination of sweat electrolyte composition. A method for taking these factors into consideration in the utilization of sweat electrolyte measurements as an index of hormonal activity is described. Finally investigations of adrenal cortical function based on this newly developed index are presented.

\section{METHODS}

Unless otherwise noted subjects were maintained on a standard diet for three to five days prior to the first col-

\footnotetext{
1This work was supported by a grant from the Commonwealth Fund of New York to the Department of Pediatrics and was aided in part by a grant from the Rockefeller Foundation to the Department of Dermatology, Harvard Medical School.

2 National Research Council Fellow, 1948-1949.
}

lection of sweat and throughout the interval during which the collections were made. The standard daily diet consisted of a low-salt diet, estimated to contain $1.5 \mathrm{gms}$. of sodium chloride, supplemented with weighed sodium chloride in such amounts as to bring the total sodium chloride intake up to $5 \mathrm{gms}$. per square meter of body surface $\left(\mathrm{m}^{2}\right)$ per day. Drinking water was allowed ad lib.

Sweating was induced by placing the subject in a room the temperature of which could be maintained at the desired level by automatic temperature regulators. Usually additional stimulation was provided by having the subject immerse one arm in a bath of warm water, the temperature of which was kept nearly constant at the value desired throughout the collection period.

Sweat was collected from the non-immersed arm by enclosing it in a loosely-fitting watertight envelope, made of rubber dental dam and fitted with a glass delivery tube at its lower end. Immediately before the envelope was placed in position, the skin of the arm was thoroughly cleaned with tap water, 70 per cent aqueous solution of ethanol and finally, distilled water.

Rates of sweating were expressed as ml. per hour per $0.1 \mathrm{~m}^{2}$ of the skin surface enclosed in the envelope, the surface area of the skin surface being calculated according to the formula of DuBois (6). The volume of sweat was taken as the sum of the free sweat delivered from the envelope plus the amount adhering to the inner surface of the envelope. The latter was determined by weighing the envelope before and after it had been wetted with sweat.

Temperatures of the room, water bath and skin were recorded by a Micromax apparatus. Separate electrodes were used in the determination of room and bath temperatures and of the skin enclosed in the rubber envelope. For the latter determination two electrodes were employed, one being fixed on the lateral surface of the arm just above the elbow and one on the dorsal surface of the forearm just above the wrist. Readings from each electrode were recorded every eight minutes during the period of collection. The reported temperature in each instance is the average of the individual readings. In these experiments, the intensity of thermal stimulation (see below) was arbitrarily taken to be the room temperature when the bath temperature was kept the same 
$\left(44.5 \pm 0.5^{\circ} \mathrm{C}\right)$ during repeated collections of sweat, or the bath temperature when the room temperature was kept the same $\left(32 \pm 0.3^{\circ} \mathrm{C}\right)$.

After collection, the sweat was filtered through Whatman No. 3 filter paper. Chloride concentrations were determined by a modification of the Volhard titration method (7) ; sodium, by the method of Butler and Tuthill (8) or by flame photometry with an internal standard; potassium, by the method of Fiske and Litarzek (9) or by flame photometry with an internal standard.

\section{RESULTS}

I. Relations between sweat chloride concentration, intensity of thermal stimulation, skin temperature and rate of sweating.
Data concerning these relations are contained in Table I, Experiments 1, 2, 3a, 4a. The subjects for these experiments were four normal adult males. Five to seven samples of sweat were collected from each subject. Collections were usually made at daily intervals.

The data demonstrate that there were great differences in the concentration of chloride in the several samples of sweat collected from each subject. For example, in the case of subject 3 the minimum concentration was $6 \mathrm{mEq}$ per L. and the maximum, $54 \mathrm{mEq}$ per $\mathrm{L}$. Coefficients of correlation (Table II) indicate that variations in

TABLE I

Data illustrating the influence of certain non-hormonal and hormonal factors on sweat electrolyte concentrations

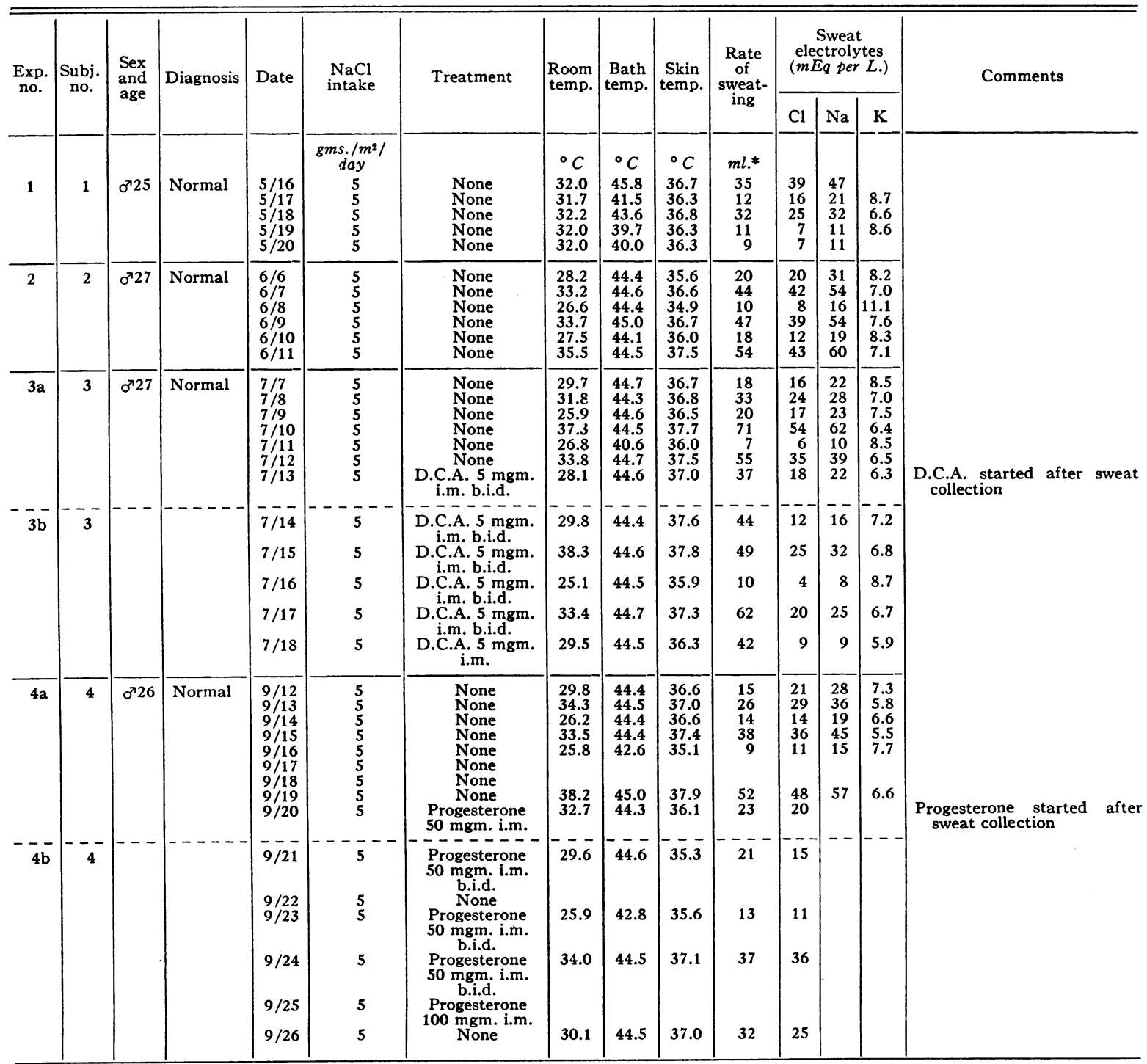


TABLE I-Continued

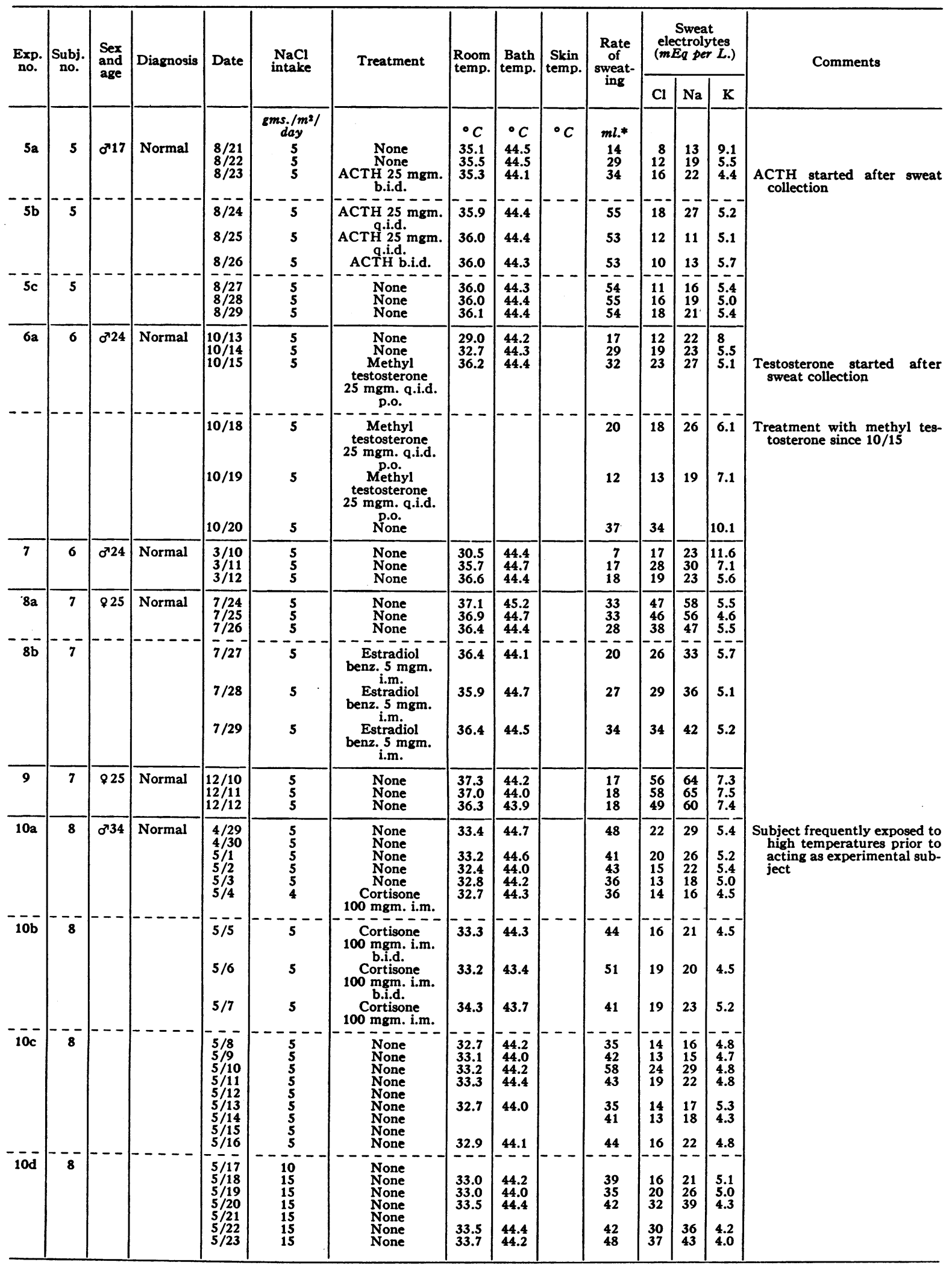


TABLE I-Continued

\begin{tabular}{|c|c|c|c|c|c|c|c|c|c|c|c|c|c|c|}
\hline \multirow{2}{*}{$\begin{array}{c}\text { Exp. } \\
\text { no. }\end{array}$} & \multirow{2}{*}{$\begin{array}{c}\text { Subj. } \\
\text { no. }\end{array}$} & \multirow{2}{*}{$\begin{array}{l}\text { Sex } \\
\text { and } \\
\text { age }\end{array}$} & \multirow{2}{*}{ Diagnosis } & \multirow{2}{*}{ Date } & \multirow{2}{*}{$\begin{array}{c}\mathrm{NaCl} \\
\text { intake }\end{array}$} & \multirow{2}{*}{ Treatment } & \multirow{2}{*}{$\begin{array}{l}\text { Room } \\
\text { temp. }\end{array}$} & \multirow{2}{*}{$\begin{array}{l}\text { Bath } \\
\text { temp. }\end{array}$} & \multirow{2}{*}{$\begin{array}{l}\text { Skin } \\
\text { temp. }\end{array}$} & \multirow{2}{*}{$\begin{array}{l}\text { Rate } \\
\text { of } \\
\text { sweat- } \\
\text { ing }\end{array}$} & \multicolumn{3}{|c|}{$\begin{array}{c}\text { Sweat } \\
\text { electrolytes } \\
(m E Q \text { per } L .)\end{array}$} & \multirow{2}{*}{ Comments } \\
\hline & & & & & & & & & & & $\mathrm{Cl}$ & $\mathrm{Na}$ & $\mathbf{K}$ & \\
\hline $11 a$ & 8 & $\sigma^{7} 33$ & Normal & $\begin{array}{l}12 / 13 \\
12 / 14 \\
12 / 15 \\
--.\end{array}$ & $\begin{array}{c}\text { gms. } / m^{2} / \\
5 a y \\
5 \\
5 \\
-\end{array}$ & $\begin{array}{l}\text { None } \\
\text { None } \\
\text { None }\end{array}$ & $\begin{array}{l}{ }^{\circ} \mathrm{C} \\
30.1 \\
-\ldots-\end{array}$ & $\begin{array}{l}{ }^{\circ} \mathrm{C} \\
44.8\end{array}$ & ${ }^{\circ} \mathrm{C}$ & $\begin{array}{c}m l . * \\
20 \\
29 \\
17\end{array}$ & $\begin{array}{l}21 \\
22 \\
11 \\
---\end{array}$ & $\begin{array}{l}27 \\
28 \\
15 \\
--\end{array}$ & $\begin{array}{l}6.2 \\
6.3 \\
5.2 \\
-\end{array}$ & $\begin{array}{l}\text { Subject frequently exposed to } \\
\text { high temperatures prior to } \\
\text { acting as experimental sub- } \\
\text { ject }\end{array}$ \\
\hline $11 \mathrm{~b}$ & 8 & & & $\begin{array}{l}12 / 16 \\
12 / 17 \\
12 / 18 \\
12 / 19 \\
12 / 20 \\
12 / 21\end{array}$ & $\begin{array}{l}5 \\
5 \\
5 \\
5 \\
5 \\
5\end{array}$ & $\begin{array}{l}\text { K supplement } \\
\mathbf{K} \text { supplement } \\
\mathbf{K} \text { supplement } \\
\mathbf{K} \text { supplement } \\
\mathbf{K} \text { supplement } \\
\mathbf{K} \text { supplement }\end{array}$ & $\begin{array}{l}33.5 \\
30.4 \\
28.8 \\
28.7 \\
28.3\end{array}$ & $\begin{array}{l}43.8 \\
45.3 \\
44.7 \\
44.7 \\
44.5\end{array}$ & & $\begin{array}{l}22 \\
27 \\
25 \\
21 \\
19\end{array}$ & $\begin{array}{l}13 \\
14 \\
14 \\
11 \\
10\end{array}$ & $\begin{array}{l}17 \\
17 \\
15 \\
13 \\
12\end{array}$ & $\begin{array}{l}9.1 \\
7.6 \\
7.3 \\
6.4 \\
6.4\end{array}$ & $\left\{\begin{array}{l}27 \text { gms. K citrate, } 745 \text { gms. } \\
\mathrm{K}_{2} \mathrm{HPO}_{4}, 3.78 \text { gms. } \\
\mathrm{KH}_{2} \mathrm{PO}_{4}, \text { added to daily } \\
\text { diet }\end{array}\right.$ \\
\hline$-\overline{11 c}$ & --- & -- & $-\cdots-\cdots$ & $\begin{array}{l}-1 / 2 \\
12 / 22 \\
12 / 23 \\
12 / 24 \\
12 / 25 \\
12 / 26 \\
12 / 27 \\
12 / 28 \\
12 / 29\end{array}$ & $\begin{array}{r}--5 \\
5 \\
5 \\
5 \\
5 \\
5 \\
5 \\
5 \\
5\end{array}$ & $\begin{array}{l}\text { None } \\
\text { None } \\
\text { None } \\
\text { None } \\
\text { None } \\
\text { None } \\
\text { None } \\
\text { None }\end{array}$ & $\begin{array}{l}--- \\
29.9 \\
29.4 \\
28.1 \\
33.7 \\
24.5\end{array}$ & $\begin{array}{l}--- \\
44 \\
44.4 \\
45.5 \\
44.9 \\
45.0\end{array}$ & - & $\begin{array}{l}12 \\
26 \\
24 \\
27 \\
11\end{array}$ & $\begin{array}{l}10 \\
17 \\
19 \\
21 \\
8\end{array}$ & $\begin{array}{l}-- \\
13 \\
21 \\
16 \\
18 \\
14\end{array}$ & $\begin{array}{l}7.3 \\
7.0 \\
3.6 \\
3.4 \\
7.9\end{array}$ & \\
\hline 12 & 9 & o'24 & Normal & $\begin{array}{l}5 / 25 \\
5 / 25 \\
5 / 25 \\
5 / 25 \\
5 / 25\end{array}$ & 15 & $\begin{array}{l}\text { None } \\
\text { None. } \\
\text { None } \\
\text { None } \\
\text { None }\end{array}$ & $\begin{array}{l}39.6 \\
41.1 \\
34.9 \\
31.2 \\
31.0\end{array}$ & $\begin{array}{l}44.4 \\
44.3 \\
44.0 \\
41.2 \\
42.9\end{array}$ & & $\begin{array}{l}60 \\
44 \\
40 \\
15 \\
24\end{array}$ & $\begin{array}{l}79 \\
72 \\
67 \\
43 \\
50\end{array}$ & $\begin{array}{l}96 \\
83 \\
78 \\
54 \\
61\end{array}$ & $\begin{array}{l}6 \\
5.2 \\
5.0 \\
5.5 \\
5.4\end{array}$ & Legs immersed in water bath \\
\hline 13 & 10 & $\sigma^{\prime 2} 24$ & Normal & $\begin{array}{l}6 / 21 \\
6 / 21 \\
6 / 21 \\
6 / 21 \\
6 / 21\end{array}$ & 24 & $\begin{array}{l}\text { None } \\
\text { None } \\
\text { None } \\
\text { None } \\
\text { None }\end{array}$ & $\begin{array}{l}41.7 \\
37.5 \\
36.5 \\
36.8 \\
36.8\end{array}$ & $\begin{array}{l}44.0 \\
44.8 \\
41.5 \\
42.1 \\
40.3\end{array}$ & & $\begin{array}{l}40 \\
17 \\
9 \\
25 \\
15\end{array}$ & $\begin{array}{l}87 \\
75 \\
52 \\
74 \\
66\end{array}$ & $\begin{array}{l}98 \\
88 \\
63 \\
81 \\
76\end{array}$ & $\begin{array}{l}4.8 \\
4.2 \\
5.6 \\
4.2 \\
4.0\end{array}$ & Legs immersed in water bath \\
\hline $14 a$ & 11 & $0^{7} 50$ & Addison's & $8 / 3$ & 2 & D.C.A. pellets & 25.0 & 44.1 & & 16 & 20 & 28 & 6.8 & \\
\hline & & & & $\begin{array}{l}8 / 4 \\
8 / 5\end{array}$ & $\mathbf{2}$ & $\begin{array}{l}\text { D.C.A. pellets } \\
\text { D.C.A. pellets }\end{array}$ & $\begin{array}{l}28.1 \\
33.6\end{array}$ & $\begin{array}{l}44.4 \\
44.3\end{array}$ & $\begin{array}{l}34.8 \\
36.6\end{array}$ & 14 & $\begin{array}{l}19 \\
26\end{array}$ & 26 & $\begin{array}{l}7.4 \\
6.4\end{array}$ & \\
\hline $14 b^{-}$ & 11 & --- & & $\begin{array}{l}8 / 9 \\
8 / 10 \\
8 / 11\end{array}$ & $\begin{array}{l}7 \\
7 \\
7\end{array}$ & $\begin{array}{l}\text { D.C.A. pellets } \\
\text { D.C.A. pellets } \\
\text { D.C.A. pellets }\end{array}$ & $\begin{array}{l}27.2 \\
32.7\end{array}$ & $\begin{array}{l}44.5 \\
44.4\end{array}$ & $\begin{array}{l}36.4 \\
37.1\end{array}$ & $\begin{array}{l}8 \\
18 \\
22\end{array}$ & $\begin{array}{l}17 \\
27 \\
34\end{array}$ & $\begin{array}{l}18 \\
36 \\
44\end{array}$ & $\begin{array}{l}5.6 \\
7.1 \\
7.2\end{array}$ & $\begin{array}{l}\text { Daily intake } \mathrm{NaCl} 7 \mathrm{gms} . / \\
\mathrm{m}^{2} / \text { day since } 8 / 5\end{array}$ \\
\hline 15 & 12 & $\mathbf{0}^{7} \mathbf{4 7}$ & $\begin{array}{c}\text { Addison's } \\
\text { disease }\end{array}$ & $\begin{array}{l}5 / 11 \\
5 / 11 \\
5 / 12\end{array}$ & $4-6$ & $\begin{array}{l}\text { None } \\
\text { None } \\
\text { None }\end{array}$ & $\begin{array}{l}34.2 \\
37.3 \\
30.3\end{array}$ & $\begin{array}{l}44.2 \\
44.1\end{array}$ & & $\begin{array}{l}3.1 \\
32 \\
15\end{array}$ & $\begin{array}{l}37 \\
88 \\
62\end{array}$ & 102 & 6 & $\underset{\text { bath }}{\text { Arm not immersed in water }}$ \\
\hline 16 & 13 & $0^{x} 48$ & $\begin{array}{c}\text { Essential } \\
\text { hyper- } \\
\text { tension }\end{array}$ & $\begin{array}{l}2 / 24 \\
2 / 25 \\
2 / 26\end{array}$ & $\begin{array}{l}5 \\
5 \\
5\end{array}$ & $\begin{array}{l}\text { None } \\
\text { None } \\
\text { None }\end{array}$ & $\begin{array}{l}37.2 \\
\\
30.8 \\
32.8\end{array}$ & $\begin{array}{l}44.3 \\
\\
44.5 \\
44.4\end{array}$ & & $\begin{array}{l}21 \\
17 \\
19\end{array}$ & $\begin{array}{l}68 \\
\\
48 \\
53\end{array}$ & 81 & $\begin{array}{l}6.4 \\
7.6 \\
6.6\end{array}$ & $\begin{array}{l}\text { Daily intake } \mathrm{NaCl} 5 \mathrm{gms} . / \\
\mathrm{m}^{2} / \text { day since } 2 / 15\end{array}$ \\
\hline 17 & 14 & O'53 & $\begin{array}{c}\text { Essential } \\
\text { hyper- } \\
\text { tension }\end{array}$ & $\begin{array}{l}3 / 27 \\
3 / 28 \\
3 / 29\end{array}$ & $\begin{array}{l}5 \\
5 \\
5\end{array}$ & $\begin{array}{l}\text { None } \\
\text { None } \\
\text { None }\end{array}$ & $\begin{array}{l}31.2 \\
\\
34.7 \\
36.7\end{array}$ & $\begin{array}{l}44.4 \\
\\
44.3 \\
44.2\end{array}$ & & $\begin{array}{l}13 \\
19 \\
26\end{array}$ & $\begin{array}{r}5 \\
7 \\
10\end{array}$ & $\begin{array}{l}11 \\
13 \\
16\end{array}$ & $\begin{array}{l}7.0 \\
\\
6.1 \\
6.3\end{array}$ & $\begin{array}{l}\text { Daily intake } \mathrm{NaCl} 5 \mathrm{gms} . / \\
\mathrm{m}^{2} / \text { day since } 3 / 18 / 50\end{array}$ \\
\hline
\end{tabular}

* Ml. per hour per $0.1 \mathrm{~m}^{2}$ of skin surface.

TABLE II

Coefficients of correlation*

\begin{tabular}{|c|c|c|c|c|}
\hline \multirow{2}{*}{ Factors correlated } & \multicolumn{4}{|c|}{ Exp. no. (Table I) } \\
\hline & 1 & 2 & $\mathbf{3 a}$ & $4 a$ \\
\hline $\begin{array}{l}\text { Rate of sweating vs. sweat chloride concentration } \\
\text { Intensity of stimulation vs. sweat chloride concentration } \\
\text { Skin temperature vs. sweat chloride concentration } \\
\text { Rate of sweating vs. intensity of stimulation } \\
\text { Rate of sweating vs. skin temperature } \\
\text { Intensity of stimulation vs. skin temperature }\end{array}$ & $\begin{array}{r}+.933 \\
+.996 \\
+.829 \\
+.998 \\
+.969 \\
+.860\end{array}$ & $\begin{array}{r}+.979 \\
+.978 \\
+.890 \\
+.998 \\
+.947 \\
+.936\end{array}$ & $\begin{array}{r}+.963 \\
+.923 \\
+.919 \\
+.879 \\
+.971 \\
+.886\end{array}$ & $\begin{array}{l}+.972 \\
+.901 \\
+.892 \\
+.887 \\
+.861 \\
+.678\end{array}$ \\
\hline
\end{tabular}

* All coefficients are statistically significant $(p<0.05)$ except those italicized. 
sweat chloride concentration were in each subject significantly correlated with $a$ ) rate of sweating, $b$ ) skin temperature and $c$ ) intensity of the thermal stimulus. In addition, they show that rate of sweating, skin temperature and the intensity of the thermal stimulus were significantly correlated with each other in almost all instances.

These findings point to a presumably nonhormonal factor capable of profoundly modifying the concentration of chloride in sweat obtained from normal subjects receiving a constant intake of sodium chloride. Consequently, it would appear that the intensity of action of the factor should be taken into consideration if sweat electrolyte composition is to be used as an index of an individual's hormonal status. Consideration of the data suggests that this may be done reasonably satisfactorily by measuring the rate of sweating. Accordingly, there follows a more detailed consideration of the relation between sweat chloride concentration and rate of sweating.

II. Detailed study of the relation between sweat chloride concentration and rate of sweating.

In all experiments summarized in Table I, data concerning this relation are recorded. Representative data drawn from this table (Experiments 3a, $3 \mathrm{~b}, 13,14 \mathrm{~b}, 15)$ are presented graphically in Figure 1.

The experiments summarized in the graph were performed on $a$ ) a normal adult male, maintained on the standard diet, both before (Curve A) and

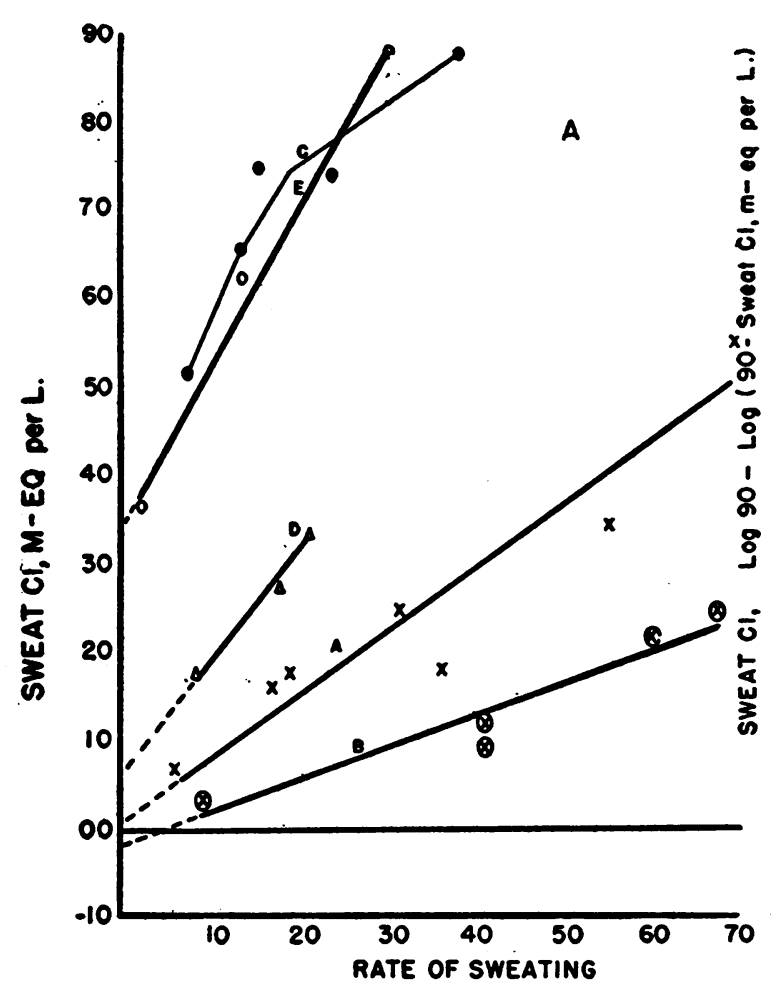

ml. per hr. per O. Im² skin surfoce.

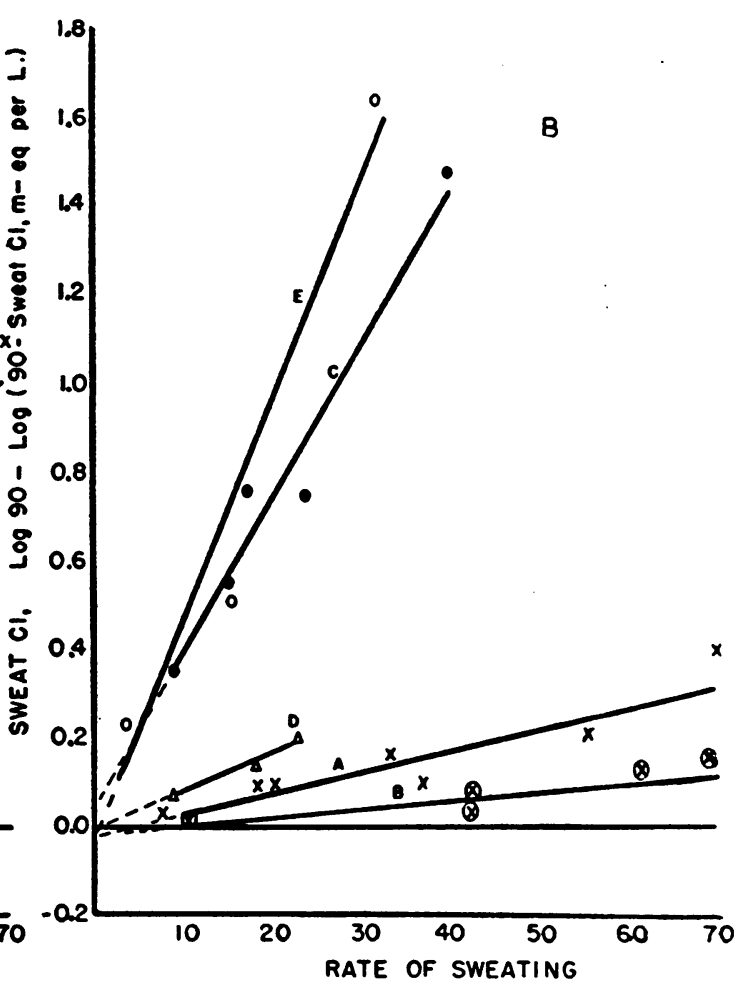

ml. per $h_{0}$ per $0.1 \mathrm{~m}^{2}$ skin surfoce.

Fig. 1. Relation between Sweat Chloride Concentration and Rate of Sweating

Data from Table I: Curve A-Experiment 3a; Curve B-Experiment 3b; Curve C-Experiment 13; Curve D-Experiment 14b; Curve E-Experiment 15. In both sections of the figure ( $A$ and $B$ ), absolute values for rate of sweating are indicated by the scale along the abscissa. In the left hand Section $A$, absolute chloride values are given according to the scale along the left hand ordinate. In the right hand Section $B$, the values indicated along the ordinate scale were found by subtracting from log 90 the log of ( 90 minus sweat chloride in $\mathrm{mEq}$ per L.). The heavy solid lines were calculated by the "method of least squares." The light solid line (Curve C, Section A) was drawn free-hand. Interrupted lines represent extrapolations of the heavy solid lines to the point where they would theoretically intersect the ordinate. The slopes of the solid lines of Section B define the value for the sweat chloride-rate index. 
while he was being given desoxycorticosterone acetate (D.C.A.), 9 mgm. b.i.d., i.m. (Curve B) ; b) a normal male maintained on a diet which provided him with $24 \mathrm{gms}$. of sodium chloride per $\mathrm{m}^{2}$ per day (Curve $\mathrm{C}$ ) ; $c$ ) an Addisonian adult male whose diet contained 6.5 gms. of sodium chloride per $\mathrm{m}^{2}$ per day and whose symptoms were well controlled by recently implanted pellets of D.C.A. (Curve D); and $d$ ) an Addisonian adult male whose diet contained approximately 5 gms. of sodium chloride per $\mathrm{m}^{2}$ per day and whose symptoms were poorly controlled by 3 D.C.A. pellets implanted eight months previously (Curve E).

Figure 1 consists of two regression graphs, A and $B$. The same data are used in each and in both the abscissa is the rate of sweating and the ordinate is sweat chloride concentration. However, for reasons which will shortly become apparent, the methods for expressing chloride concentration differ.

In Figure 1-A chloride concentrations are expressed simply as $\mathrm{mEq}$ per $\mathrm{L}$. of sweat. Note in this figure that in all instances there was an increase in the concentration of chloride as the rate of sweating increased. However, the properties of the curves describing the relation between the two variables appear to be very different. In four instances (Curves $\mathrm{A}, \mathrm{B}, \mathrm{D}$ and $\mathrm{E}$ ) linear regression lines describe the relation satisfactorily but on extension they intercept the ordinate at widely different points ( -1.8 to $+33.2 \mathrm{mEq}$ per L.). In the fifth instance (Curve $\mathrm{C}$ ), the relation clearly is not linear.

Figure 1-A also shows that sweat chloride concentration measurements do not per se always permit one to distinguish between sweat from individuals subjected to different degrees of stimulation by the adrenal cortex or administered D.C.A. However, inspection of the figure reveals that such a distinction can be made if chloride concentration is viewed with relation to rate of sweating. Although evident on inspection, differences between the curves of Figure 1-A cannot be described and quantitated satisfactorily in simple arithmetic terms.

Because it seemed highly desirable to have a generally applicable, simple arithmetic method describing the relation between chloride concentration and rate of sweating, other methods of ex- pressing the data were sought. Examination of available data suggested that the relation between sweat chloride concentration and rate of sweating might be described satisfactorily by a series of catalytic curves asymptotic at a chloride concentration of approximately $90 \mathrm{mEq}$ per L. Accordingly, to test this possibility values for sweat chloride concentration were expressed as $\log 90$ minus log (90 minus sweat chloride concentration in $\mathrm{mEq}$ per $\mathrm{L}$.). The resultant values have been plotted (ordinate) against rate of sweating (abscissa) in Figure 1-B. Note that in this graph all curves are linear and all, on extension, intercept the ordinate very close to the origin. Differences between them consist only in differences in slope. This fact permits the relation between sweat chloride concentration and rate of sweating to be represented with fair accuracy by dividing the ordinate by the abscissa value. The magnitude of the resultant quotient is directly proportional to the slope of the curve. For convenience, this quotient, expressed as a simple number, will be called the sweat chloride-rate index. This index is used henceforth to indicate relations between chloride concentration and rate of sweating.

III. Relations between the concentration of chloride, sodium, and potassium in thermal sweat.

In the preceding and following sections of this paper, attention is restricted to the response of chloride ion to the various stimuli which affect sweat electrolyte composition. The present section indicates the extent to which chloride concentration measurements are representative of sweat sodium and potassium.

Figure 2 demonstrates by means of regression graphs relations between the concentration of chloride and $a$ ) the concentration of sodium, $b$ ) the concentration of potassium and $c$ ) the ratio, $(a) /(b)$, as determined in 57 different specimens of thermal sweat. Fifty-one of the 57 specimens were collected from normal subjects. Of these 35 came from subjects eating the standard diet. Twenty-three of the 35 specimens were collected from subjects who were not receiving hormonal treatment; the remaining 12 specimens were collected from subjects being treated with D.C.A. Seven specimens were collected from a subject whose daily diet contained a great excess of sodium over chloride ( $220 \mathrm{mEq} \mathrm{Na}, 12 \mathrm{mEq} \mathrm{Cl}$ ) 


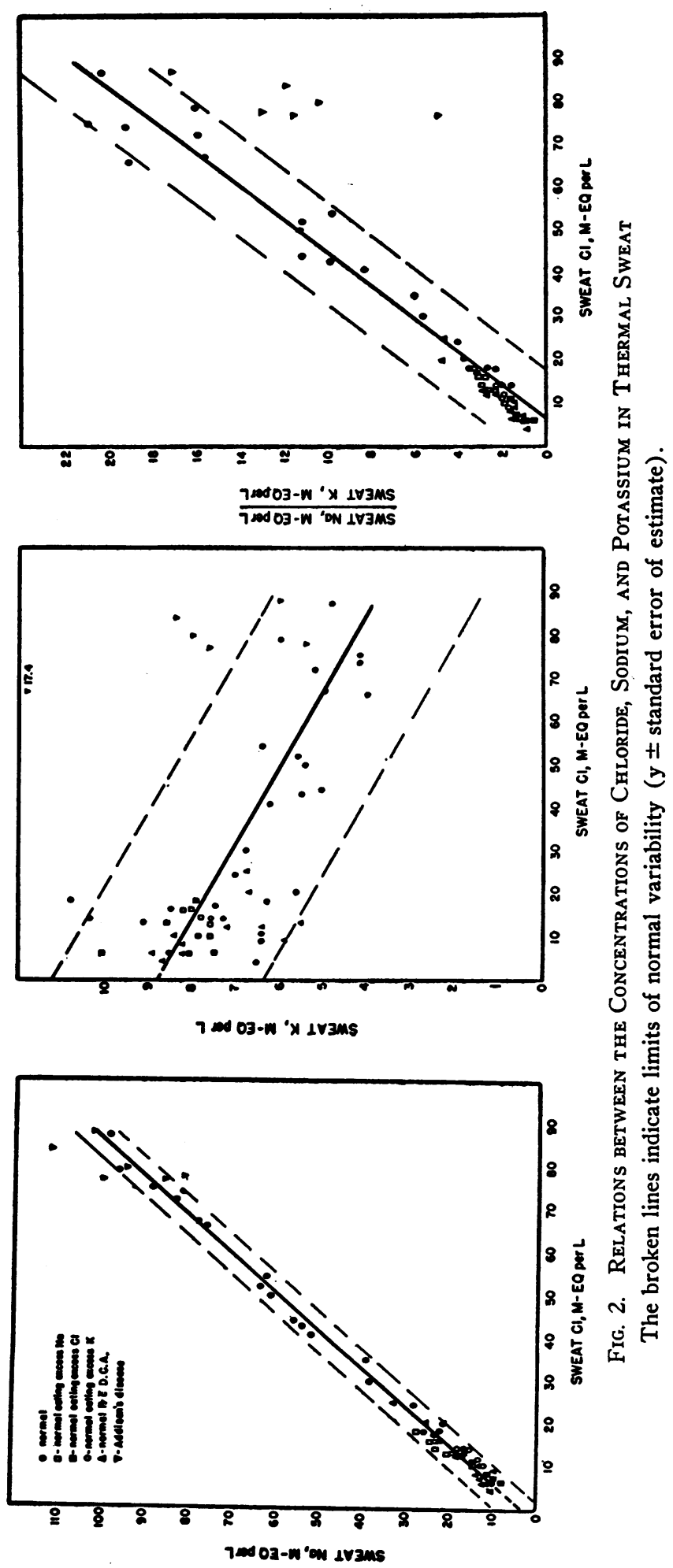




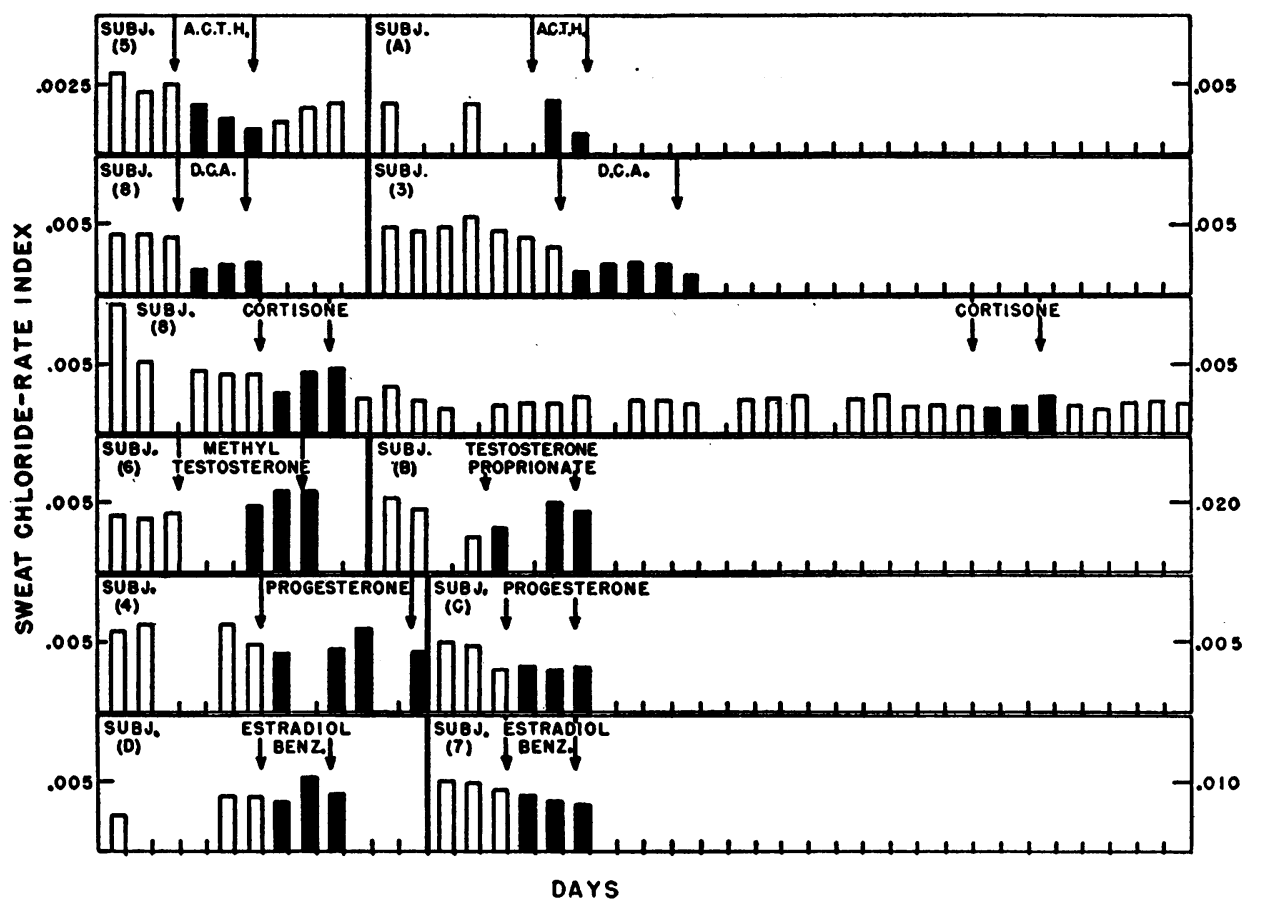

Fig. 3. The Effect of Certain Hormones on the Sweat Chloride-Rate Index

ACTH $25 \mathrm{mgm}$. q.i.d.; D.C.A. $5 \mathrm{mgm}$. b.i.d.; Cortisone $75 \mathrm{mgm}$. and $100 \mathrm{mgm}$. b.i.d.; Methyl testosterone $25 \mathrm{mgm}$. q.i.d.; Testosterone propionate $100 \mathrm{mgm}$. q.d.; Progesterone $50 \mathrm{mgm}$. b.i.d.; Estradiol benzoate $5 \mathrm{mgm}$. q.d. Subjects are designated by number if data are included in Table I.

and four were collected from the same subject when his daily diet contained a great excess of chloride over sodium ( $15 \mathrm{mEq} \mathrm{Na}, 220 \mathrm{mEq} \mathrm{Cl}$ ). Five specimens were obtained from a subject whose basal (standard) daily diet was supplemented with large amounts of potassium salts $(370 \mathrm{mEq} \mathrm{K})$. Six specimens were collected from patients having poorly controlled Addison's disease.

In the sweats from the untreated normal subjects eating the standard diet, the relation between the concentration of chloride and each of the other three variables is linear. These relations, expressed mathematically were:

a) $[\mathrm{Na}]=1.12[\mathrm{Cl}]+3 \mathrm{mEq}$ per L. (standard error of estimate $2.6 \mathrm{mEq}$ per L.)

b) $[\mathrm{K}]=0.056[\mathrm{Cl}]+8.8 \mathrm{mEq}$ per L. (standard error of estimate $1.2 \mathrm{mEq}$ per L.)

c) $[\mathrm{Na}] /[\mathrm{K}]=0.26[\mathrm{Cl}]-1.7$ (standard error of estimate, 1.52).

The coefficients of correlation between chloride concentration and each of the other three variables are all significant. As the concentration of chlo- ride rises the concentration of sodium and the ratio between the concentrations of sodium and potassium rise while the concentration of potassium falls.

The values for the 11 samples of sweat from the individual eating the diets grossly abnormal with respect to their electrolyte contents all fell within the range of normal variability. ${ }^{3}$ In the 12 samples of sweat collected from individuals treated with D.C.A. all values fell within the "normal range" except for one value for potassium concentration which fell below the normal range. In the six samples of sweat obtained from patients having poorly controlled Addison's disease, in relation to the concentration of chloride, a) three sodium concentrations fell within, two fell above and one fell below the normal range, $b$ ) two potassium concentrations fell within and four above the normal range and $c$ ) all six ratios between the con-

3 The normal range of variability was taken to be $y \pm 2$ standard error of estimate where $y$ is [Na], [K] or $[\mathrm{Na}] /[\mathrm{K}]$. Such a range includes 96 per cent of determinations. 
centrations of sodium and potassium were below the normal range.

\section{Relations between sweat chloride index} and hormonal status.

A. The effect of certain hormones on the sweat chloride-rate index. In this series of experiments one subject, who received ACTH, had rheumatoid arthritis. All other subjects were normal. Cortisone acetate was given to one subject on two occasions. Methyl testosterone and testosterone propionate were each given to one subject. The other hormones were each given to two subjects. Methyl testosterone was taken by mouth. The other hormones were administered intramuscularly. The hormones and dosages employed were as follows: Adrenocorticotropic hormone (Armour Standard ACTH) 25 mgm. b.i.d. or q.i.d. (see Table I); desoxycorticosterone acetate (D.C.A.) (Percorten, Ciba) 5 mgm. b.i.d.; cortisone acetate (Cortone, Merck) $75 \mathrm{mgm}$. b.i.d. on one occasion and $100 \mathrm{mgm}$. b.i.d. on another; methyl testosterone (Oreton-M, Schering) 25 mgm. q.i.d.; testosterone propionate (Oreton, Schering) $100 \mathrm{mgm}$. daily; progesterone (Proluton, Schering ) $50 \mathrm{mgm}$. b.i.d.; estradiol benzoate (Progynon-B, Schering) $5 \mathrm{mgm}$. daily. In most instances the hormones were administered over a three to five day period.

Figure 3 represents the results of these experiments. The administration of either ACTH or D.C.A. was accompanied by striking reductions in the value of the index in all instances. The administration of methyl testosterone was accompanied by a significant rise in index values. While cortisone, progesterone and testosterone propionate had no statistically significant effect on the sweat chloride-rate index, inspection of the data suggests that their administration was associated with a slight rise in index values. It is possible that longer administration of cortisone would have resulted in a tendency to lowered index values. In one instance the administration of estradiol benzoate was accompanied by a significant reduction in the index; in the other instance this hormone had if anything an opposite effect.

B. A comparison of the sweat chloride-rate index in normal and hypoadrenocortical subjects. Figure 4 presents measurements of the sweat chloride- rate index obtained as a result of the first sweating in the cases of a) 10 normal subjects (seven male, three female) eating the standard diet during the summer; $b$ ) nine normal subjects (five male, four female) eating the standard diet during the winter; c) seven hypoadrenocortical subjects of which three were male and four female. Collections of sweat were made from the hypoadrenocortical patients during both seasons of the year. One of these patients ate the standard diet. The others were on hospital diets estimated to contain 4-6 gms. of sodium chloride per $\mathrm{m}^{2}$ per day.

In the normal subjects eating the standard diet, the average value for the index was during the summer .0054 (range .0029 to .0097 ) and during the winter .0165 (range .0111 to .0249 ). In the hypoadrenocortical subjects the average was .1095 (range .0348 to .1809). In none of the three groups did the sex of the subject appear to affect the index value.

V. The sweat chloride-rate index in studies of adrenal function in man.

A. Effect of varying the dietary intake of sodium chloride and potassium salts. Figure 5 portrays data obtained in experiments involving one normal male (Table I, Experiments No. 10c-d), one diabetic female and one patient having Addison's disease (Table I, Experiments No. 14a-b). Their dietary intakes of sodium chloride per day varied

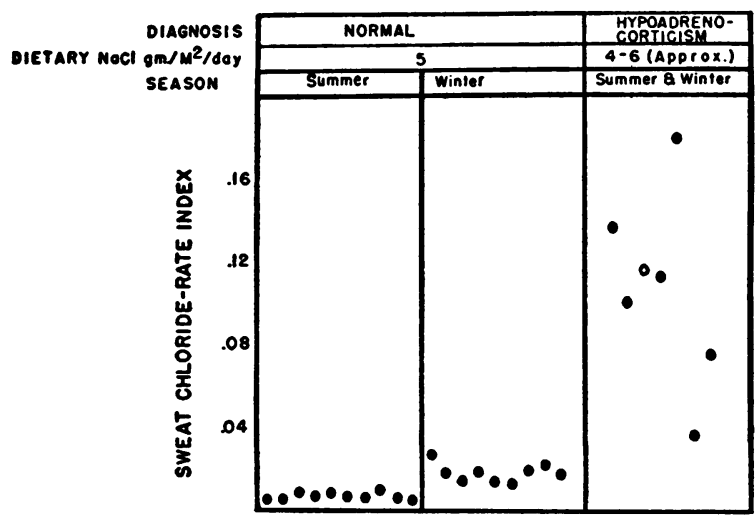

Fig. 4. Sweat Chloride-Rate Indices for the First Sweating of Normal and HypoadrenocortiCal Subjects

In the hypoadrenocortical group, black circles represent patients with primary adrenal cortical insufficiency and the single white circle represents a patient with hypoadrenocorticism secondary to hypopituitarism. 


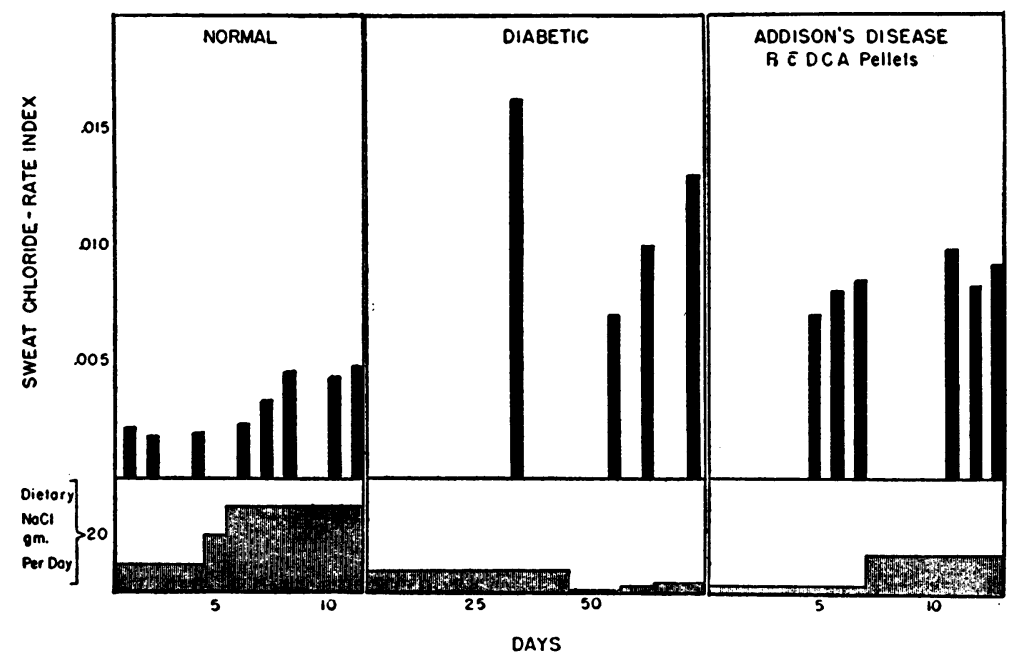

Fig. 5. The Effect on the Sweat Chloride-Rate Index of Varying Dietary Sodium Chloride

Differences noted in the normal and diabetic subjects following changes in dietary $\mathrm{NaCl}$ intake are statistically significant; the difference between the two groups of values obtained in the Addisonian patient is not statistically significant.

between 10 and 30 gms., 0.6 and 8.6 gms. and 3.5 and 11.5 gms., respectively. Note that the sweat chloride-rate index closely parallels the sodium chloride intake in the normal and in the diabetic subjects. In the Addisonian patient, no statistically significant change in the index value occurred.

In Experiments 12 and 13, Table I, two normal male subjects were given diets containing very large amounts of sodium chloride (15 and 24 gms. per $\mathrm{m}^{2}$ per day, respectively) for 10 days. At the time of the first sweating the respective sweat chloride-rate indices were .0152 and .0369 , the latter being within the range observed for patients with untreated Addison's disease. The range of indices in 10 comparable normal subjects on the standard diet is .0029 to .0097 (Figure 4).

Figure 6 describes the effect on the sweat chloride-rate index of a normal male of adding 27 gms. of potassium citrate, 8.02 gms. of dipotassium phosphate and $3.78 \mathrm{gms}$. of monopotassium phosphate $(370 \mathrm{mEq}$ of $\mathrm{K})$ to a standard diet. Note that the index value was significantly lower during the high potassium period than during two control periods.

B. Effects of exposure to heat. Figure 7 describes the effect on the sweat chloride-rate index of normal subjects of $a$ ) season (see also Figure 4) and $b$ ) repeated sweating. It is evident that the indices are considerably lower during the "summer" (May 1 to October 31) than during the "winter" (November 1 to April 30). In the winter, but not in the summer, there is a well defined tendency for index values to fall when the subject

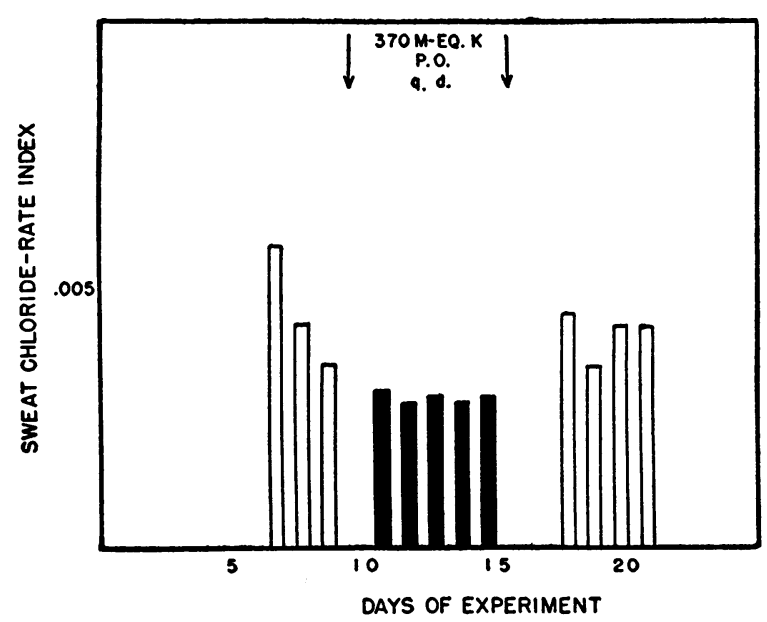

Fig. 6. The Effect on the Sweat Chloride-Rate Index of Increasing the Dietary Intake of PotasSIUM SALTS

The values during the high potassium period are significantly different from the control values. 
is sweated repeatedly on consecutive days. The observations of Figure 7 plus other incomplete data suggest that between three and approximately eight consecutive days of hourly exposure to intense heat are required to induce a drop in index values from average winter to average summer levels.

C. Hypertension. Figure 8 shows the sweat chloride-rate indices of four patients suffering idiopathic hypertension. These measurements were carried out during the winter. The patients had been maintained on diets low in sodium (estimated to contain about $1 \mathrm{gm}$. of sodium chloride per $\mathrm{m}^{2}$ per day) for from five to 20 months prior to the beginning of the experiments. For the first 10 days of the experiment, during which no sweat was collected, and for the subsequent two to three days during which collections were made at daily intervals, they were maintained on the standard diet.

It is seen that sweat chloride-rate indices for two of the patients fell within the normal range (Figure 7); in the other two patients the values definitely were subnormal.

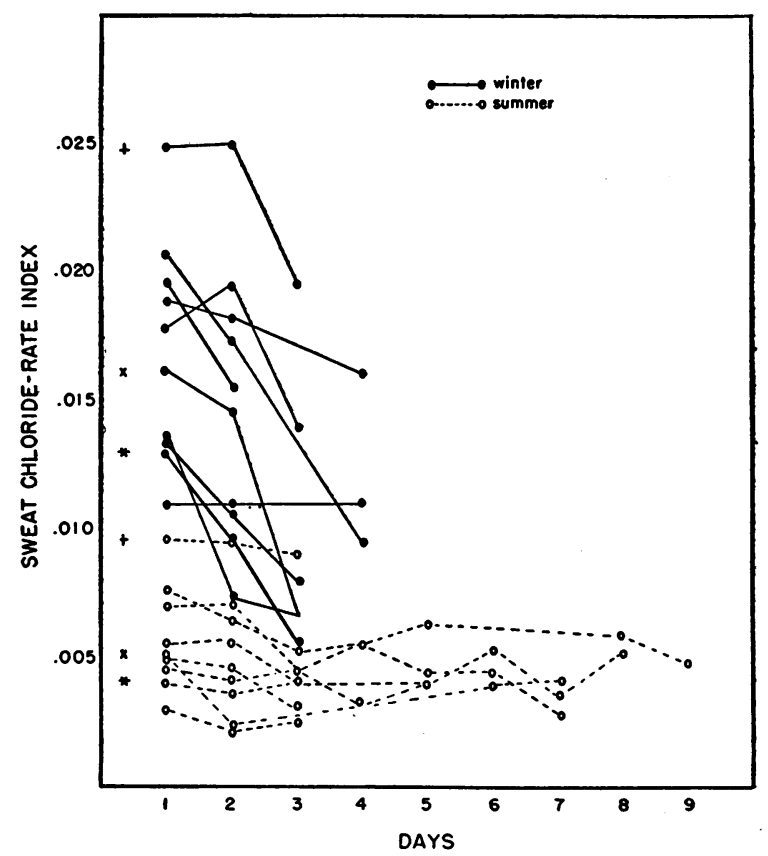

Fig. 7. The Effect of Season and Repeated Sweatings on the Sweat Chloride-Rate Index

At the left of some of the curves are symbols. Each type of symbol represents a single individual. Thus repeat studies on the same individual can be recognized by symbol duplication.

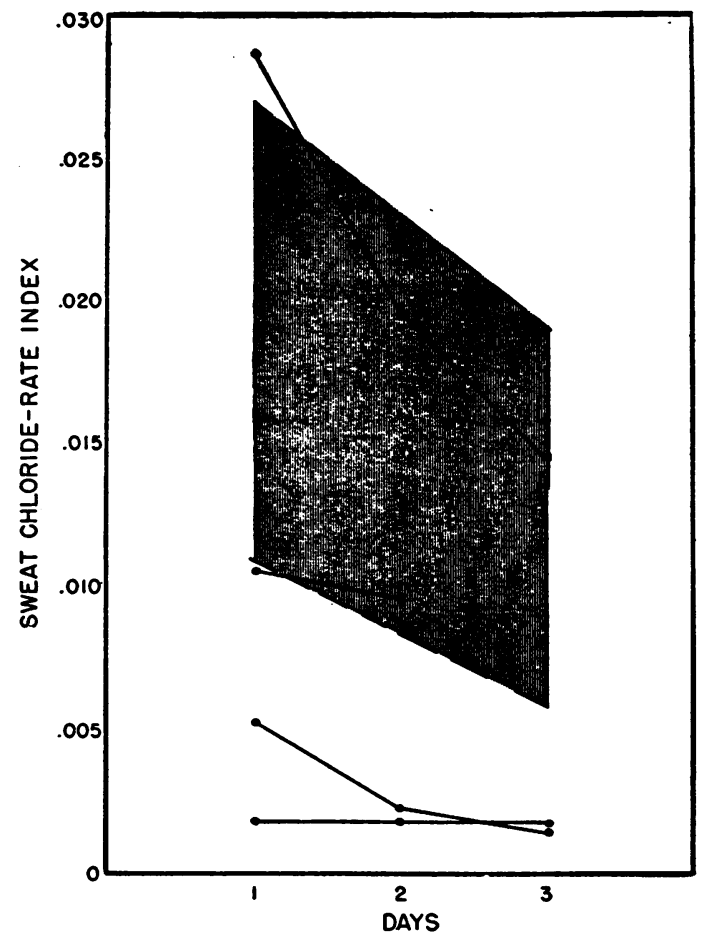

Fig. 8. Values for the Sweat Chloride-Rate Index of Four Hypertensive Subjects

These values were obtained during the winter. The shaded area gives the range of values obtained on normal subjects during the same season as indicated in Figure 7.

\section{DISCUSSION}

The initial studies described in this report show clearly that sweat electrolyte composition is influenced almost as much by non-endocrine factors related to intensity of thermal stimulus, skin temperature and rate of sweating as by active adrenal cortical hormones. Under conditions of constant hormonal status, sweat electrolyte concentrations bear a mathematically predictable relation to these non-endocrine variables. A change in intensity of action of hormones which influence sweat formation results in an alteration in sweat electrolyte composition relative to thermal stimulus, skin temperature and rate of sweating.

The sweat chloride-rate index was evolved in an effort to express such changes in sweat electrolytes relative to these non-hormonal factors in a practically useful manner. Values for the concentration of chloride bear a closely predictable direct relation to those of sodium and an approximate, inverse relation to those of potassium in 
sweat. Hence chloride may be considered satisfactorily representative of the other two sweat electrolytes. Rate of sweating does not always bear a close relation to intensity of thermal stimulus or skin temperature. On the other hand, it usually is roughly proportional to these variables. Rate of sweating is closely correlated with sweat chloride concentration when the dietary and hormonal status are maintained constant. Because of this and the fact that rate of sweating is readily measureable, it was selected to represent the nonendocrine factors in the index equation.

The observations on hypoadrenocortical patients coupled with the hormone administration studies provide clues concerning the probable nature of endocrine factors responsible for changes in sweat chloride-rate index values. Index values were consistently higher than normal in hypoadrenocortical patients. Desoxycorticosterone acetate was the only one of the steroid hormones to induce a marked decrease in the index value. This occurred within one day. Interestingly, 17-hydroxy11-dehydrocorticosterone (cortisone) induced if anything a slight rise in index values over a period of three days.

These data suggest that sweat chloride-rate index values bear an inverse relation to the concentration of adrenal cortical hormones which, like desoxycorticosterone, act chiefly upon body electrolyte and water metabolism (10). Adrenocorticotropic hormone induced as great and as rapid a fall in the index value of normal subjects as did desoxycorticosterone acetate. It therefore appears that the human adrenal cortex secretes a hormone with desoxycorticosterone-like properties in response to adrenocorticotropin stimulation.

While the estrogens and androgens given were not wholly without effect upon sweat chloride-rate index values, they did not appear to exert a striking and consistent regulatory influence. This suggests that their influence upon sweat formation may have been accomplished indirectly by stimulating or inhibiting pituitary adrenocorticotropic hormone production rather than by direct action upon the sweat glands. Inhibition of adrenocorticotropic hormone secretion and hence of adrenal cortical activity might account for the slight rise in index values observed following cortisone, progesterone and testosterone. This thesis is compatible with the fact that cortisone and methyl testosterone act to suppress adrenal cortical urinary 17-ketosteroid precursor production, presumably by inhibiting adrenocorticotropin secretion (11, 12). Methyl testosterone also can inhibit 11-17oxycorticosteroid excretion (13). The single observation that estradiol may induce a lowering of index values likewise is in keeping with the fact that estrogens can cause adrenal cortical hyperplasia by stimulating secretion of adrenocorticotropic hormone (14).

The foregoing considerations lead to the conclusion that sweat chloride-rate index values are determined chiefly by adrenal cortical hormones of the 11-desoxycorticosterone type. A rise in index values therefore suggests a decrease, and a fall in index values an increase in adrenal cortical activity.

The present studies of adrenal cortical status based on measurements of this index extend and confirm observations of other workers which suggest that the adrenal cortices undergo physiologic alterations in activity in response to certain situations (14-16). Thus the consistent tendency for the sweat chloride-rate index to fall when normal persons are subjected to low sodium chloride diets, high potassium diets or repeated exposure to heat indicate that these factors induce a physiologic increase in adrenal cortical activity. By contrast, high sodium chloride diets prompt the index values of normal persons to rise to levels comparable to those observed in patients with primary hypoadrenocorticism. The fact that no significant changes in index values took place in a hypoadrenocortical patient when the salt intake was varied indicates that the changes observed in normal subjects were dependent upon the presence of functionally intact adrenal cortices.

The comparative observations on the normal subjects taking a high sodium diet and on the hypoadrenocortical patients indicate that under certain circumstances absolute rates of adrenal cortical secretory activity attained physiologically may closely approximate those observed in patients with adrenal cortical pathology. Similar information is provided by studies of urinary 11-17-oxycorticosteroid excretion in health and disease (17). In other words, pathologic is distinguished from physiologic adrenal cortical function by the relation of secretory activity to physiologic, homeo- 
static needs rather than by absolute differences in secretory rate.

Preliminary observations on patients with idiopathic hypertension indicate that the sweat chloride-rate index may provide interesting diagnostic information in certain presently obscure diseases. Two of the four patients studied had values suggestive of pathologic hyperproduction of the electrolyte-water regulating type of adrenal cortical hormone.

\section{SUMMARY AND CONCLUSIONS}

1. Intensity of thermal stimulus, skin temperature and rate of sweating bear an important relation to sweat electrolyte composition. Certain hormones act to modify sweat composition relative to these factors. Such hormonal action can be appraised by use of an index which expresses sweat chloride concentration values relative to rate of sweating.

2. Studies suggest that the chief determinant of sweat chloride-rate index values is an adrenal cortical hormone which, like desoxycorticosterone, acts chiefly upon electrolyte and water metabolism.

3. Measurements of the sweat chloride-rate index suggest strongly that the normal adrenal cortices can undergo wide variations in activity in response to physiologic, homeostatic needs. Under physiologic conditions, adrenal cortical production of desoxycorticosterone-like hormones may subside to levels comparable to those existing in patients with primary pathologic hypoadrenocorticism.

4. The possibility that the sweat chloride-rate index measurement may have diagnostic value in miscellaneous conditions is exemplified by preliminary observations on four patients with idiopathic hypertension.

\section{ACKNOWLEDGMENTS}

The supplies of cortisone used in these studies were generously provided by Merck and Co. We are indebted to the Schering Corporation for the other steroids and to the Armour Co. for the ACTH used in these investigations. We also wish to acknowledge our gratitude to Drs. C. Frazier and I. H. Blank of the Dermatology Service of the Massachusetts General Hospital for the use of their air conditioned room and micromax apparatus.

\section{REFERENCES}

1. Conn, J. W., Louis, L. H., Johnston, M. W., and Johnson, B. J., Electrolyte content of thermal sweat as an index of adrenal cortical function. $J$. Clin. Invest., 1948, 27, 529.
2. Conn, J. W., Electrolyte composition of sweat; clinical implications as an index of adrenal cortical function. Arch. Int. Med., 1949, 83, 416.

3. Kittsteiner, C., Sekretion, Kochsalzgehalt und Reaktion des Schweisses. Arch. f. Hyg., 1911, 73, 275.

4. Hancock, W., Whitehouse, A. G. R., and Haldane, J. S., The loss of water and salts through the skin, and corresponding physiologic adjustments. Proc. Roy. Soc., London, s. B., 1929, 105, 43.

5. Johnson, R. E., Pitts, G. C., and Consolazio, F. C., Factors influencing chloride concentration in human sweat. Am. J. Physiol., 1944, 141, 575.

6. DuBois, E. F., Basal Metabolism in Health and Disease. Lea and Febiger, Philadelphia, 1924.

7. Wilson, D. W., and Ball, E. G., A study of the estimation of chloride in blood and serum. J. Biol. Chem., 1928, 79, 221.

8. Butler, A. M., and Tuthill, E., An application of the uranyl zinc acetate method for determination of sodium in biological material. J. Biol. Chem., 1931, 93, 171.

9. Folin, O., Laboratory Manual of Biological Chemistry. D. Appleton-Century Co., New York, 1934, Ed. 5.

10. Swingle, W. W., and Remington, J. W., The role of the adrenal cortex in physiological processes. Physiol. Rev., 1944, 24, 89.

11. Wilkins, L., Lewis, R. A., Klein, R., and Rosemberg, E., The suppression of androgen secretion by cortisone in a case of congenital adrenal hyperplasia. Preliminary report. Bull. Johns Hopkins Hosp., 1950, 86, 249.

12. Reifenstein, E. C., Jr., Forbes, A. P., Albright, F., Donaldson, E., and Carroll, E., Effect of methyl testosterone on urinary 17 -ketosteroids of adrenal origin. J. Clin. Invest., 1945, 24, 416.

13. Talbot, N. B., Albright, F., Saltzman, A. H., Zygmuntowicz, A., and Wixom, R., The excretion of 11-oxycorticosteroid-like substances by normal and abnormal subjects. J. Clin. Endocrinol., 1947, 7, 331.

14. Tepperman, J., Engel, F. L., and Long, C. N. H., A review of adrenal cortical hypertrophy. Endocrinology, 1943, 32, 373.

15. Conn, J. W., The mechanism of acclimatization to heat, in Advances in Internal Medicine. Interscience Publishers, Inc., New York, 1949, Vol. 3, p. 373.

16. Deane, H. W., Shaw, J. H., and Greep, R. O., Effect of altered sodium or potassium intake on width and cytochemistry of zona glomerulosa of rat's adrenal cortex. Endocrinology, 1948, 43, 133.

17. Talbot, N. B., Zygmuntowicz, A. N., Wood, M., and Christo, E., Observations on adrenal cortical "sugarfat-nitrogen" hormone ("11-17-OCS") and "17ketosteroid precursor" production by normal and abnormal individuals of various ages with comments on the fact that (a) there may be two ACTH's and (b) the normal adrenal cortex may not produce true androgens, in Proc. First Clinical ACTH Conference, J. R. Mote, Editor. The Blakiston Co., Philadelphia, 1950, p. 32. 